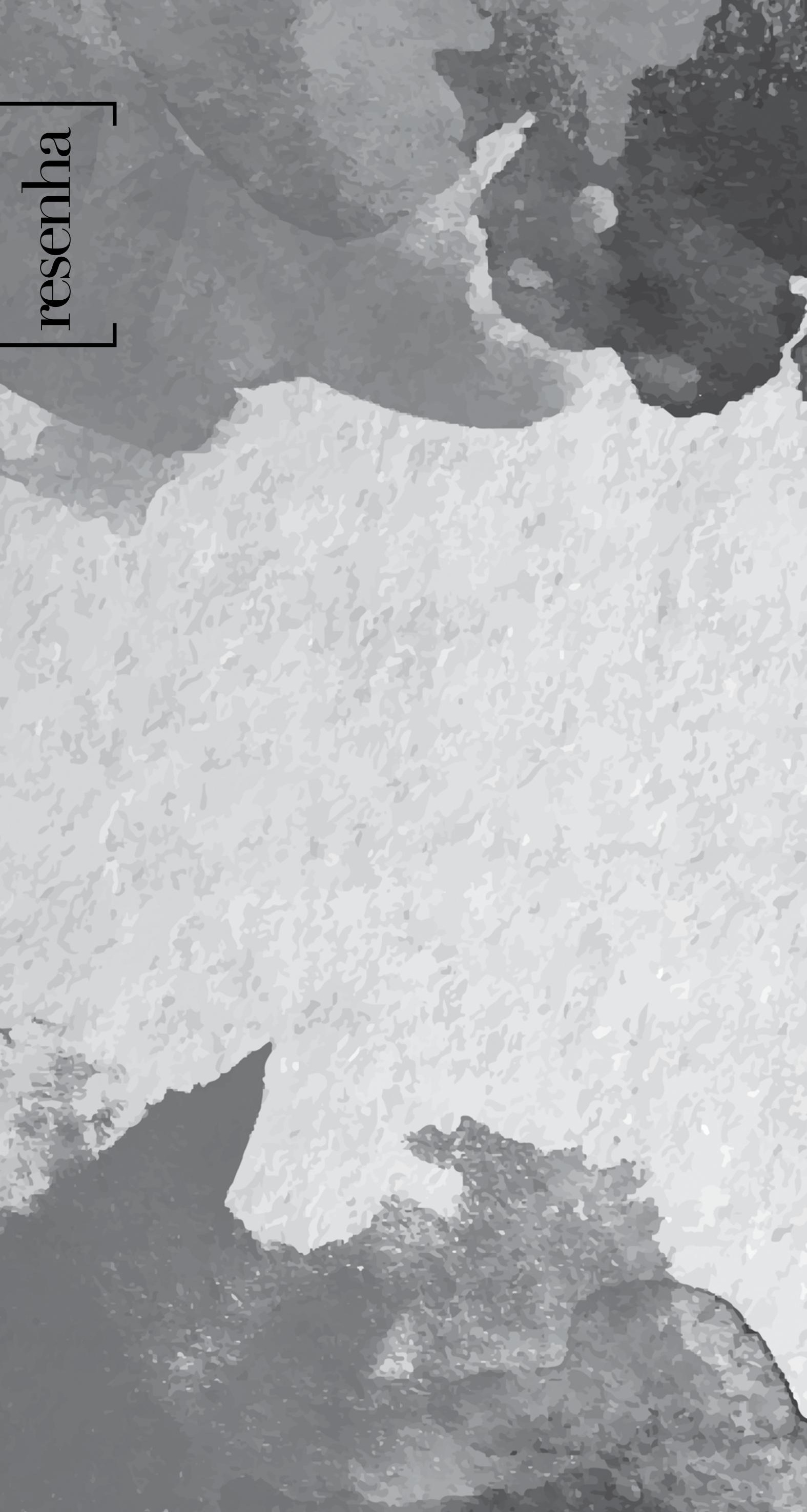




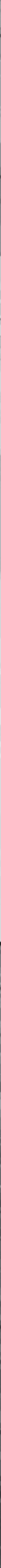


resenha de exposição]

\section{As roupas, as coisas e os conceitos: notas exploratórias sobre uma exposição de arte}

Arte na moda: coleção MASP Rhodia.

Curadoria: Adriano Pedrosa, Patrícia Carta e Tomás Toledo.

Local e periodo: Museu de Arte de São Paulo. São Paulo, 23 de dezembro de 2015 a 14 de fevereiro de 2016. 
Nos anos 1960 e 1970, eram famosos os desfiles que a Rhodia, indústria quimica francesa voltada para a produção de tecidos sintéticos com sede no Brasil, produzia para a Feira Nacional da Indústria Têxtil, a Fenit. De certo modo, eles ficaram cristalizados na memória afetiva dos que acompanham o universo da moda como o momento em que a moda brasileira, seus costureiros, modelos e criadores eram efetivamente trazidos a público. Eram desfiles-show, "um espetáculo que unia moda, artes visuais, teatro, dança e música" (SANT'ANNA, 2015, p. 29). A exposição Arte na moda: coleção MASP Rhodia nos trouxe de volta esse sabor, sendo assim um convite a uma visita ao passado. Mas um passado rodeado pela pulsante realidade nacional. Pois se $o$ ápice dos desfiles da Rhodia se deu em plena ditadura militar, a exibição de hoje ocorre abrigada pelo espaço do museu sediada, contudo, em um ambiente de vibrantes diferenças. A Avenida Paulista, que aos domingos se converte em área de passeio e lazer, igualmente é palco de manifestações políticas, de modo que foi um MASP heterogêneo que encontramos naquele novembro de 2015. Seu vão livre, tomado pela já tradicional feirinha de antiguidades, encontrava-se rodeado por faixas empunhadas por feministas que pediam a saída de Eduardo Cunha da presidência da Câmara dos Deputados e povoado por bandeirolas carregadas por senhoras que davam seu apoio a Israel, entre outras manifestações de posicionamento político. Foi assim que uma Paulista manhosa (e democrática?) nos recebeu naquele domingo de mormaço e calor intensos.

Dentro do museu, a realidade urbana fica para trás e a exposição nos conduz, junto à experiência estética, a um experimento intelectual. Esta resenha não pretende assim descrever a exposição, as peças à vista ou dar uma mostra do acervo que a Rhodia doou ao MASP, relato essencial a que temos acesso por meio dos ensaios do simpático catálogo que pôde ser adquirido de modo igualmente agradável: ao lado do totem onde foram empilhadas as brochuras, inserimos dez reais em uma pequena urna e pegamos o delicado livro². Pois, para além dos belos exemplares indumentários, queremos explorar aqui uma inquietação que de imediato no Primitivism in 20th Century Art nos acometeu ao adentrar o espaço da exposição, causada inicialmente pelas legendas que acompanham as peças de roupa.

A exposição mostra a coleção doada pela Rhodia ao MASP, em 1972, reunida a partir da escolha pessoal de Pietro Maria Bardi, diretor-fundador do museu, a convite da empresa, como informa o catálogo. 0 acervo é composto de peças de roupas confeccionadas em tecido sintético produzido pela Rhodia e estampado por grafismos criados por artistas plásticos nacionais renomados. Nas legendas que acompanham os itens expostos podemos notar um recorrente apagamento da identidade do estilista, que repetidamente consta como "desconhecido". Por outro lado, os criadores do grafismo sobre o tecido, em sua grande maioria identificada pelo trabalho de pesquisa de acervo, possuem seus nomes grafados em destaque. A mesma lógica ordena o catálogo da exposição. Os nomes dos artistas estão explicitados e destacados em negrito como contraste às outras informações que acompanham a imagem. Menções ao estilista (conhecido ou não), o tipo de tecido empregado e a descrição da peça de roupa (saia, calça, vestido, blusa, túnica, macacão, palazzo pijama): todas essas são informações impressas em fonte padrão e sem destaque.

E não se trata apenas de nomes serem ou não revelados. Mas o grande número de artistas plásticos em face do número reduzido de estilistas (são 34 artistas contra 9 estilistas) nos fala não apenas de um processo de individuação, mas também da individualização inerente ao nosso reconhecimento do trabalho 
enquanto "artístico" em contraste a um trabalho em escala mais massiva, como seria o do estilista. A definição de artista ocidental ecoa a ideologia do individualismo moderno, sendo assim uma espécie de paroxismo seu. 0 artista é aquele que exerce sua criatividade e a partir de sua genialidade cria de modo a se libertar das amarras da sociedade. A genialidade o distinguiria assim na massa de pessoas ditas comuns.

Por outro lado, o estilista, cuja identidade aparece em segundo plano na escala de autoria das peças de roupas exibidas, ocupa lugar análogo ao que foi outorgado ao artista popular, como na exposição Primitivism in 20th Century Art, montada em Nova York, nos anos 1980. Esta desencadeou um debate que provocou desdobramentos fundamentais não só para as políticas da representação - mais especificamente o modo pelo qual a arte etnográfica seria representada nos museus -, como para a definição de arte e artista a partir do tensionamento causado pelas aproximações e distinções entre arte e artefato. É, em continuidade a essa discussão, que tomamos a exposição no MASP como ensejo para refletirmos sobre a relação entre arte, moda e design.

Pois a mostra montada no segundo subsolo do MASP, de certo modo, espelha uma noção de arte e artista que vem sendo desconstruída não apenas pelas reflexões acadêmicas, como também pelos próprios artistas contemporâneos. Além disso, ver o estilista silenciado traz ainda uma ironia. No sistema de moda atual, ao estilista é outorgado o lugar de artista, o grande criador, enquanto o modelista - aquele que efetivamente encontra a solução para que o projeto do artista de fato se concretize - e ainda os costureiros - que não apenas executam a peça, mas colaboram para que ela venha à tona - permanecem no anonimato. Essas categorizações, contudo, derivam de uma cisão entre arte e técnica que na prática não se institui. Pois, se acompanharmos o dia a dia de um estilista, como alguns recentes filmes documentários e ficcionais nos deixam ver, nota-se que, na verdade, essa criação se faz de modo pulverizado e compartilhado, residindo não na intenção de um, mas na intenção de muitos $^{3}$.

Portanto, temos aqui uma primeira pista da problemática que iremos acompanhar. Na verdade, o silenciamento passado do estilista, como nos mostra a exposição no MASP, versus a sua evidência contemporânea corresponde a uma percepção de que arte e técnica se opõem. Seriam assim campos separados da vida social. Uma separação para a qual Walter Benjamin já chamara a atenção ao apontar a perda de "aura" que pela qual passaria o objeto de arte na época de sua reprodutibilidade técnica (BENJAMIN, 2012). Benjamin estava interessado nas consequências que as novas tecnologias imagéticas trariam para o nosso conceito e entendimento de arte. Contudo, algumas apropriações dessa sua reflexão reificaram a cisão entre arte e técnica, fazendo confundir técnica com reprodução mecânica.

0 trabalho manual e a artesania seriam, desse viés, pura reprodução mecânica e repetição, puro acompanhamento de regras. Não à toa a terminologia estilista se aplica ao profissional contemporâneo. Dener, Ugo Castellana, Jorge Farré, para citar os nomes mais recorrentes no acervo Rhodia MASP, eram chamados à época de costureiros, título que destaca justamente o aspecto manual de suas atividades em vez do caráter criativo e intelectual que hoje atribuímos ao estilista. 0 que se afina com o lugar menos de artista e mais de artesão que ocupa o estilista na organização museográfica da coleção Rhodia.

0 título da exposição, Arte na moda, alude a essa separação. Pois o criador da estampa, do grafismo, é o "artista", aquele que produzirá a "arte," que será, por sua vez, inserida em um campo outro, o campo da moda, que criaria em um regime alternativo definido, dessa perspectiva, como não arte. 0 catálogo, mais uma vez, remete a essa concepção ao organizar a mostra das criações a partir do ordenamento alfabético dos nomes dos artistas. Aquele que criou o grafismo está, portanto, no foco, o que provoca um apagamento não apenas do costureiro/estilista, 
mas também do conjunto de autores que concorreram para que a referida obra de arte se concretizasse. Portanto, como nota uma das curadoras da exposição, as peças de vestuário da coleção MASP contribuíram para "dessacralizar" a noção de arte e aproximaram de um público mais amplo os artistas antes "confinados em galerias e museus" (CARTA, 2015, pp. 18-20). Mas o desafio da autoria múltipla que essas roupas apresentam, como mostram as legendas e explicita outro dos curadores da mostra (PEDROSA, 2015), parece ter sido dissolvido pelo contexto no qual essas peças são agora apresentadas. A autoria múltipla coloca um problema não apenas para a noção de arte ocidental como igualmente desestabiliza as regras que regem os espaços dos museus e as coleções de arte.

As políticas da representação seguem propondo desafios para as curadorias dos museus no mundo ${ }^{4}$. Mas a discussão sobre quem é ou não artista está relacionada ainda a outro debate: a distinção entre arte e objetos de uso cotidiano - no nosso caso especificamente, a moda se converte em suporte exemplar para a discussão, pois, ao se referir fundamentalmente à roupa e aos outros objetos indumentários, ela diz respeito ao usável, ao vestível (wearable) e, portanto, à estética com a qual adornamos nossas ações cotidianas. Aponta assim para uma tensão, entre arte e artefato, que tem norteado as discussões em torno da definição de arte, uma discussão interdisciplinar que tomou especial vulto nas últimas décadas do século $X X$.

A exposição Primitivism in 20th Century Art de 1984, mencionada acima, intencionou mostrar o lugar que as artes africanas tiveram no desenvolvimento da arte moderna ocidental, um estilo artístico que a história da arte chamou de Primitivismo. A proposta da exposição norte-americana em si mesma não seria um problema, não fosse pelo modo com o qual representou como a influência estética dos artistas africanos e suas criações se exerceu. Objetos retirados de seus paises de origem, muitos deles já inseridos em coleções de arte primitiva sediadas nos Estados Unidos, foram colocados lado a lado de produções de artistas do porte de Pablo Picasso e Alberto Giacometti sem que seus autores tivessem seus nomes registrados, tampouco seus contextos de origem foram mencionados. Essa descontextualização obedeceu um interesse duplamente motivado. Uma vez descontextualizados, os objetos, do ponto de vista da curadoria, teriam seu valor estético revelado ao público, algo que os antropólogos não teriam sabido revelar ao remetê-los constantemente aos seus contextos de produção. Em outros termos, os itens deveriam ter sua função e sua utilidade em suas sociedades originárias apagadas para que tivessem seu valor artístico revelado. Estética e função, dessa perspectiva, são aspectos que não se comunicam, reforçando mais uma vez a noção de arte que aloca os objetos artísticos em espaços extraordinários, distanciados do uso cotidiano. Mas esses povos, como ainda ficaria evidente em outra exposição, não separavam qualidades estéticas e sensoriais das funcionais e utilitárias.

Art/Artefact: African art in anthropology collection, montada em 1988 no Centro de Arte Africana de Nova York, buscou responder justamente a essa questão. Ao reproduzir quatro diferentes espaços expositivos - a galeria de arte, 0 gabinete de curiosidades, o museu de arte e o museu etnográfico -, Susan Vogel, antropóloga e curadora da mostra, revelou como o objeto oscilava entre arte e artefato de acordo com o contexto físico e institucional de sua exposição. Vogel colocou para o público uma armadilha, como Alfred Gell posteriormente argumentaria (2001). Dobrou, iluminou e acomodou uma rede de caça Zande, etnia africana, de maneira tal que poderia ser lida como uma obra de arte contemporânea pelo público iniciado na sensibilidade das galerias de arte voltadas para a exibição dessa produção. 
0 ponto levantado por Gell, feito junto a seu projeto de reformulação da Antropologia da Arte, foi o de que a função do objeto guardava precisamente a chave para o apreendermos como um objeto de arte. Não eram, ou não eram somente, as qualidades estéticas ou os aspectos representacionalistas que poderiam responder por seu significado, mas a rede de caça Zande, como próprio das armadilhas, era um nódulo de intencionalidades: a do seu idealizador, isso é, aquele que procederia à captura, a da presa, uma vez que era preciso conhecê-la para saber como capturá-la, e ainda a de um possível ancestral mítico criador. 0 importante para nossa reflexão aqui é que, ao se afastar do critério de beleza para definir a arte - critério este que já não regia mais o campo das artes contemporâneas -, Gell distanciou-se tanto da ideia de indivíduo como criador único quanto da ideia de arte como oposta ao mundo da utilidade e da instrumentalidade.

Após esse tour pelas exposições norte-americanas, podemos retornar ao MASP e junto com o acervo da Rhodia no museu elaborarmos um pouco mais sobre as relações entre arte, moda e design. Pois, se como disse o filósofo Arthur Danto (1988), os objetos de arte são aqueles capazes de nos colocar em contato com "realidades maiores" - em contraste com os artefatos que nos remeteriam a valores corriqueiros porque cotidianos -, as roupas, como vimos no acervo da Rhodia no MASP, permitem aceder a valores que nos são caros e, nesse sentido, são objetos de arte plenos de significado 5 .

Portanto, se nos anos 1980 o desafio colocado derivou das tensões entre arte e artefato, a provocação, no espaço do MASP, poderia ter sido a de desestabilizar o espectador, convidando-o a problematizar suas concepções de artista e criação ao coadunar a definição de arte com a de autoria múltipla, trazendo assim para dentro do museu a discussão iniciada pela Rhodia ainda nos anos 1960.

Cada roupa, como observa Adriano Pedrosa no catálogo da coleção do MASP, "impõe um desafio particular, pois há vários autores e colaboradores no processo de fabricação de cada peça: 0 artista, o estilista, a confecção, a estamparia e a fábrica de fios" (PEDROSA, 2015, pp. 7-8). Esse traço, contudo, não é exclusivo do artefato, pois sabemos que os objetos de arte definidos em senso estrito são eles mesmos produtos de uma rede de profissionais que colaboram dentro e fora do ateliê do artista, participando do processo de "generação" de sua forma (INGOLD, 2012). Um trabalhou na resolução gráfica da imagem, outro preparou o fundo da tela, outro ainda esboçou a imagem a ser reproduzida, ou mesmo a pintou.

Ao adentrar o espaço do museu ou da galeria de arte, a autoria múltipla desaparece de modo que o enigma que a coisa coloca para o espectador é solucionado por meio do conceito. Conceitos que certamente vêm sendo modificados junto com os problemas que a vida coloca para a arte. E as roupas, como vimos na exposição Arte na moda, concedem oportunidade impar para esse movimento. Elas nos instigam a questionar a ordem das coisas embaralhando não apenas as diferenças entre arte e artefato, mas as definições de artista criativo e criatividade e do próprio mercado. 


\section{NOTAS}

[1] Pesquisa financiada por bolsa CAPES-PNPD/Institucional.

${ }^{[2]}$ Arte na moda: coleção MASP Rhodia. Curadoria: Adriano Pedrosa, Patricia Carta e Tomás Toledo. São Paulo: MASP, 2015.

${ }^{[3]}$ Ver, entre outros, Dior e eu, de Frédéric Tcheng, e Yves Saint Laurent, de Jalil Lespert.

${ }^{[4]}$ Ver, entre outros, as reflexões de Clifford (1988), Gonçalves (2007) e Lagrou (2008).

[5] 0 mesmo nos mostram diferentes pesquisas contemporâneas. Eu mesma, ao explorar a estética musical e corporal no universo funk, e em particular sua indumentária, cheguei a noções relativas à pessoa, à corporalidade, ao gênero, à crença e à religiosidade. Ver, entre outros, A estética funk carioca: criação e conectividade em Mr. Catra.

\section{REFERÊNCIAS}

BENJAMIN, Walter. A obra de arte na era de sua reprodutibilidade técnica. In: Benjamin e a obra de arte: técnica, imagem, percepção. CAPISTRANO, T. (Org.). Rio de Janeiro: Contraponto, 2012, pp. 9-40.

CARTA, Patrícia. Arte na moda: coleção MASP Rhodia. A arte na moda: coleção MASP Rhodia./curadoria, Adriano Pedrosa, Patrícia Carta, Tomás Toledo. São Paulo: MASP, 2015.

CLIFFORD, James. The predicament of culture: twentieth-century ethnography, literature and art. Cambridge: Harvard University Press, 1988.

DANTO, Arthur. Artefact and art. VOGEL, Susan et. al. (Orgs.). Art/Artefact: African art in Anthropological Collections. Catálogo da exposição. Nova lorque: Centre for African Art \&t Prestel Verlag, 1988, pp. 18-32.

GELL, Alfred. A rede de Vogel: armadilhas como obras de arte e obras de arte como armadilhas. In: Arte e Ensaios: Revista do Programa de Pós-Graduação em Artes Visuais. Rio de Janeiro: Escola de Belas Artes da UFR, ano 8 (8): 174-191, 2001.

GONÇALVES, José Reginaldo. Antropologia dos objetos: coleções, museus e patrimônios. Rio de Janeiro: Garamond, 2007.

INGOLD, Tim. Trazendo as coisas de volta à vida: emaranhados criativos num mundo de materiais. Horizontes Antropológicos, ano 18, n. 29, pp. 25-44, jan./jun. 2012.

LAGROU, Elsje. A arte do outro no Surrealismo e hoje. Horizontes Antropológicos, ano 14, n. 37, pp. 217-230, jan./jun. 2008.

MIZRAHI, Mylene. A estética funk carioca: criação e conectividade em Mr. Catra. Rio de Janeiro: 7Letras 2014.

PEDROSA, Adriano. Rhodia no MASP: coleção MASP Rhodia. A arte na moda: coleção MASP Rhodia./ curadoria, Adriano Pedrosa, Patrícia Carta, Tomás Toledo. São Paulo: MASP, 2015.

PEDROSA, Adriano, CARTA, Patrícia e TOLEDO, Tomás. A arte na moda: coleção MASP Rhodia. Catálogo da exposição. São Paulo: MASP, 2015.

SANTANNA, Patricia. Coleção Rhodia: arte e moda no Brasil dos anos 1960. A arte na moda: coleção MASP Rhodia./curadoria, Adriano Pedrosa, Patricia Carta, Tomás Toledo. São Paulo: MASP, 2015. 